\title{
Associated factors of self-reported psychopathology and health related quality of life among men who have sex with men (MSM) with HIV/AIDS in Dalian, China: a pilot study
}

Tesfaldet Habtemariam Hidru', Feng Wang ${ }^{1}$, Sainyugu Lolokote', Yong Jia ${ }^{2}$, Min Chen², Wei Tong ${ }^{3}$ and Xiao-Feng Li ${ }^{1 *}$

\begin{abstract}
Background: Despite the availability of Anti-Retroviral Therapy (ART), the health-related quality of life (HRQoL) among HIV-positive men who have sex with men (HIVMSM) in China remains poor. This study aimed to explore the relationship between self-reported psychopathology and HRQOL among HIVMSM in Dalian, China.

Methods: A cross-sectional study was conducted in 112 HIVMSM. Symptom check list 90 (SCL 90): a measure of psychopathology and World Health Organization quality of life in HIV infection (WHOQOL-HIV-Bref): a measure of HRQoL were used. Correlation and multiple regression analysis were employed to explore the association between self-reported psychopathology and HRQoL in HIVMSM.
\end{abstract}

Results: Out of the total 112 HIVMSM cases, 9 (8 \%) cases were homosexuals and 103 (92\%) ones were bisexuals. The participants who had low family income $(P=0.001)$, perceived discrimination $(P=0.001)$ and lack of regular attendance in medical follow-ups $(P=0.014)$ reported poorer HRQoL than their counterparts. Somatization, obsession, depression, phobia and overall SCL 90 scores in self-reported psycholpathology had a negative impact on the domains of HRQOL among HIVMSM.

Conclusions: Total quality of life was predicted by family income, perceived discrimination, and medical follow-up attendance. Self-reported psychopathology was negatively correlated with HRQoL in HIVMSM. The Strategies that target MSM focusing on linking and engaging HIV-positive patients in medical care is the key step to improve their HRQoL. More emphasis is needed on the newly diagnosed HIVMSM in Dalian in order to develop a more targeted intervention to prevent perceived discrimination and lack of proper medical follow-up services.

Trial registration: The trial registration number does not require for this manuscript. The study is cross-sectional design that do not involve intervention at all, it is not a clinical trial.

Keywords: Men who have sex with men, HIV/AIDS, Psychopathology, Mental health, Health related quality of life

\footnotetext{
*Correspondence: Ixf_chen@163.com; li_xf75@yahoo.com

'Department of Epidemiology and Biostatistics, Dalian Medical University,

Dalian, Liaoning 116044, People's Republic of China

Full list of author information is available at the end of the article
} 


\section{Multilingual abstracts}

Please see Additional file 1 for translations of the abstract into the five official working languages of the United Nations.

\section{Background}

Sexual orientation among men who have sex with men (MSM) is not only culturally and psychologically considered abnormal in China, but also highly discriminated against, as it is considered a high risk for HIV infection. The HIV epidemic and incidence among MSM continues to rise at an alarming rate [1], however the percentage of HIV occurrence in MSM in China used to be relatively low compared to other Asian countries such as Cambodia (7.8 \%), Indonesia (9.0\%), and Thailand (24.6\%) [2]. According to the reported statistics in 2002, Chinese MSM represents about 2 to $5 \%$ of the sexually active male population [3]. In recent years, the male-tomale homosexual transmission has become one of the major modes of HIV transmission [4, 5], and the proportion of newly diagnosed HIV cases due to male homosexual contact has increased from $12.2 \%$ in 2007, 21.4\% in 2013, to $23.4 \%$ in 2014, respectively in China [6, 7]. The HIV incidence had increased in Liaoning Province from 5.1 to $10.2 \%$ during 2007-2009 [8], and the HIV infection rate among MSM increased from $4.48 \%$ in 2009 to $12.00 \%$ in Dalian in 2012 [9].

The city of Dalian is in Liaoning province as a peninsula in the Huanghai and the Bohai Sea with an elaborate coastline. It's beautiful beaches and close proximity to Korea and Japan make it both a domestic and international tourist destination in summer. This flow of people carves and modifies the disposition of local Dalian cultural morays along with the associated sex business with increasing connections via the internet. Although the Chinese society is relatively conservative on sexual issues, the increased number of visitors may impact the culture of the society at large.

The development of highly active antiretroviral therapy (HAART) for HIV/AIDS has helped the patients tremendously in coping with the chronic, complex and unpredictable course of the disease [10-12]. The multiple and complex factors of personality traits [13, 14], age [15] sociocultural stigmatization [16], psychological elements, discrimination and disclosure of HIV/AIDS status pose a substantial challenge to the concept of HRQoL issues among HIV/AIDS infected individuals/ patients [17]. Consequently, the aforementioned factors can provoke psychopathological problems and may eventually lead to subnormal quality of health (QoL).

Attitudes towards sex and sexual behaviors have changed throughout eons of cultural revolution in China, however, sexual attitudes towards homosexual engagement are not yet well acceptable and official institutionalization among the gay population is lacking. This is primarily due to the reason that the Chinese society associates a negative connotation to homosexuality and considers it as an aberrant and unacceptable behaviour [18, 19]. Though physical and psychological distress is common amongst the people living with HIV/AIDS [20], the negative implication of the cultural influence and HIV infection might lead to psychosocial instability, which eventually affects the HRQoL of HIVMSM. Also, the emergence of psychopathology and HRQoL is a common observation among the people living with HIV/AIDS [21].

Although a lot of work has been carried out on the risk of HIV/AIDS in the MSM population prior to their infection, far less work has been done to assess the factors that influence the mental health of the HIVMSM post-infection. Until a few years ago, the focus of most researches was on the investigation of HRQoL among the general HIV population and knowledge, attitude and practice towards HIV infection, prevention and test for HIV infection among MSM rather than the mental health wellbeing and HRQoL post-HIV infection. These studies have indicated that socio-demographic characteristics i.e. age, gender, ethnicity, education level, marital status, employment, and transmission route seem to be the primary influential factors affecting the quality of life of the people living with HIV/AIDS [22-24]. Also, the findings from the study related to the quality of life for people living with HIV/AIDS revealed that the factors such as younger age, single, not farmers, and higher education level, high level of CD4 count and good ART adherence tend to have positive effects on QoL [25].

Despite the increased recognition of MSM wellbeing and mental health issues in many parts of China, there is paucity of data on their HRQoL, particularly in Dalian. Also, it is important to consider the alternative foci of research that addresses the post infection mental wellbeing and HRQoL of affected MSM. The present study was designed to assess the self-reported psychopathology and HRQoL for HIVMSM and to explore the associated factors. Since the WHOQOLHIV- Bref [26] and SCL 90 [27] have proven to be reliable for the assessment of the quality of life and self-reported psychopathology of Chinese people with HIV/AIDS, they were selected to indicate the QoL and self-reported psychopathology in this study. The present study included perceived discrimination, living conditions, and medical follow-up attendance which were not assessed in the earlier studies.

\section{Methods}

A cross-sectional survey of patients aged $>18$ years who attended the Center for Disease Control (CDC) in Dalian was conducted. This was a pilot study that 
targeted the newly diagnosed MSM with HIV/AIDS. All HIVMSM who visited the CDC between December 2012 and December 2013, who were returning to the CDC for antiretroviral treatment follow-up were invited to participate. The patients who were older than 18 years, had sex with men, HIV-infected and exclusively diagnosed in the year of 2012 were eligible for this survey. Patients who had no sexual history with men and were diagnosed earlier or later than 2012, or were transferred from the other parts of China were excluded.

Participants were interviewed using a structured questionnaire to obtain demographic and clinical information, quality of life, and the presence and severity of psychological symptoms. Public health professionals who were trained specifically to collect the data for this study were involved in administering the questionnaires. Newly diagnosed MSM with HIV/AIDS was defined as HIVMSM who had their seropositivity for the first time in year 2012. Income was measured at the household level and classified into 3 groups: low ( $<2000$ Yuan), middle (2 000-4 000 Yuan) and high income ( $>4000$ Yuan). Fear of discrimination was assessed subjectively by asking the participants about their agreement and disagreement $(1=$ yes, $2=$ no $)$ with a question that assesses if they perceive discrimination from the community or health professionals because of being MSM with HIV/AIDS. Living conditions were determined from the participants' response (yes or no) to a question whether they are living alone or with family/partner/friend/relative. Medical follow-up attendance was assessed by if the patients regularly attended their follow-up services. Their response recorded $1=$ regular or $2=$ not regular.

Psychopathology was measured by a Chinese version of SCL-90; a reliable, valid and accepted tool for psychological evaluation [27]. This regimen has been used in several studies in China $[28,29]$ to explore the presence and severity of psychological symptoms. There are nine subscales of SCL-90 namely; (somatization, obsessivecompulsive, interpersonal sensitivity, depression, anxiety, anger/hostility, phobic anxiety, paranoid ideation and psychoticism). SCL-90 is scored using a five-point scale (0 to 4 ) to measure the symptoms experienced in the last 7 days. Higher scores indicate more severe psychopathologic symptoms on the SCL- 90 .

Participants were appraised for quality of life by WHOQOL-HIV-Bref, a cross-cultural instrument that contains 31-items and six domains. The six domains included in this study were physical, psychological, independence, social relationships, environment, and spirituality, as used in other studies. This selfadministered questionnaire explores the issues pertaining to capacity, frequency and intensity or satisfaction. Each item was rated on a five-point Likert scale (1 to 5), with higher scores indicating better functioning. The multidimensional evaluations of the respondents' health and social life-related conditions were based on how they

Flow Chart of the recruited and participated HIVMSM

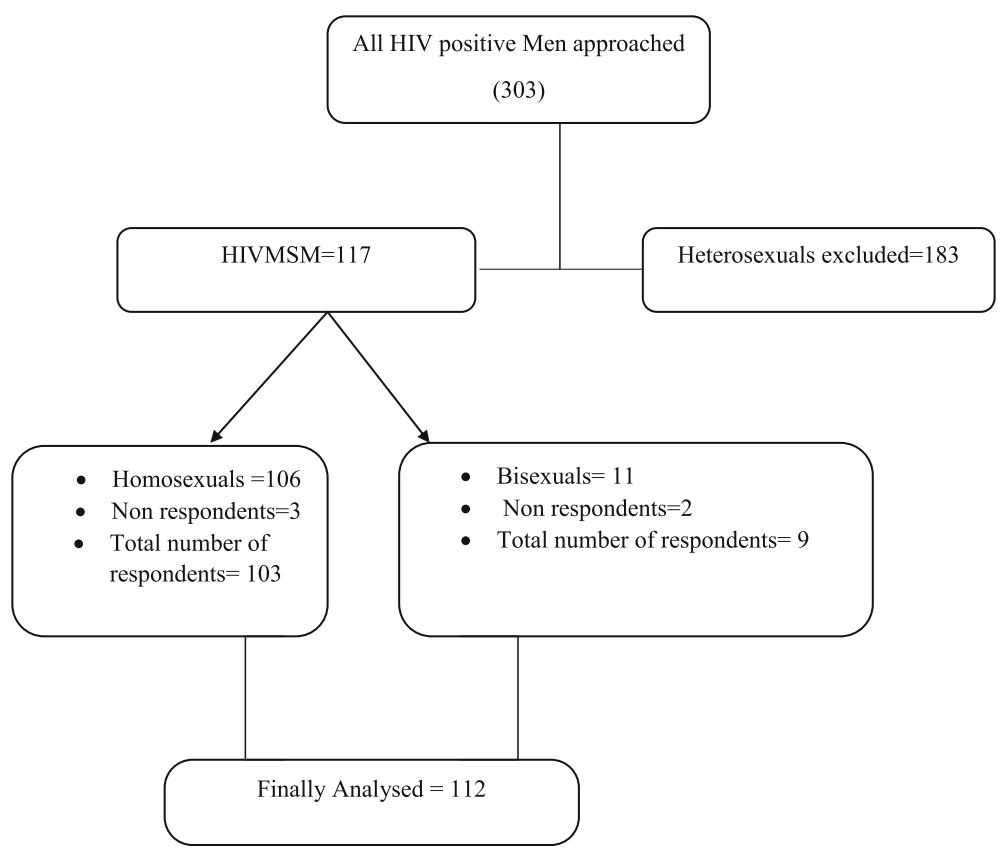

Fig. 1 Flow chart of the recruited and participated HIVMSM 
rate themselves on their daily living activities in all aspects of their lives. The Chinese version of WHOQOL-BREF has been widely used and validated in China $[25,30]$.

A total of 303 HIV-positive men were reported in Dalian in 2012. In the first stage, all HIV-positive men were included in the study. In the second stage, the HIV-positive men were classified into two groups (HIVMSM and heterosexuals) based on their response to their sexual preferences. A total of 117 HIVMSM were identified and included in this study while 186 heterosexuals were excluded from the study. In the third stage, the 117 HIVMSM were classified into homosexuals $(n=106)$ and bisexuals $(n=11)$. All 117 HIVMSM were approached and only 112 (97.5 \%) HIVMSM (homosexuals $(n=103)$ and bisexuals $(n=9)$ ) participated in this study. Figure 1 demonstrates the flow chart of the recruited and participated HIVMSM.

The data were entered in Epidata 3.1 software to get optimized documentation and error detection, which was further analyzed using IBM SPSS (Statistical Package for Social Sciences), version 21. The differences in psychopathology and HRQoL among the nominal variables of demographic characteristics were tested using independent $t$-tests or one-way analysis of variance (ANOVA). Pearson's product-moment correlation coefficients were obtained to examine the associations between the continuous variables of demographic characteristics (age and CD4 + T cell count) and, total SCL 90 scores and total HRQoL. The relationship between the self-reported psychopathology (as measured by SCL90) and HRQoL (as measured by the WHO HRQOL-BREF) was also investigated using Pearson's product moment of correlation. Spearman rank order correlation was used with ranked demographic variables (Marital status, education, family income, employment, living condition, perceived discrimination, sexual behavior and medical follow-up). Multiple regression analyses were conducted to explore the factors that associate with selfreported psychopathology and HRQoL in MSM with HIV/AIDS. The assumptions of normality, independence, linearity and homoscedasticity were checked with a residual analysis. Multicollinearity was assessed for all variables by means of correlation coefficients, tolerances, and the variance inflation factors. Neither assumptions were violated nor was multicollinearity detected. A $P$ value of $<$ 0.05 was considered significant.

\section{Results}

Sociodemographic and clinical characteristics, and self-reported psychopathology and HRQoL

Table 1 shows socio-demographic characteristics of MSM with HIV/AIDS. Out of the total 112 MSM with HIV/AIDS, 9 (8\%) were homosexuals and 103 (92\%) were bisexuals. The mean age of the participants was
Table 1 Sociodemographic and clinical characteristics of MSM with HIV/AIDS $(n=112)$

\begin{tabular}{lll}
\hline $\begin{array}{l}\text { Demographic and } \\
\text { Clinical Characteristics }\end{array}$ & $n(\%)$ & \\
\hline Age & Mean $=34.31$ & Median $=31$ \\
& Range $=18-73$ &
\end{tabular}

Marital status

Married/co-habiting $16(14.3)$

Single $\quad 78(69.6)$

Divorced/widowed $18(16.1)$

Education level

Junior high school $\quad 30(26.8)$

and below

High school or technical 35 (31.3)

secondary school

College and above $\quad 47(42)$

Employment

Employed 84 (75)

Nonemployed $\quad 28(25)$

Income

$\begin{array}{ll}\text { Low } & 36(32.1) \\ \text { Moderate } & 50(44.6) \\ \text { High } & 26(23.2) \\ \begin{array}{l}\text { Living condition } \\ \text { With family/partner/ }\end{array} & 79(70.5) \\ \text { friend/relative } & \\ \text { Living alone } & 33(29.5) \\ \begin{array}{l}\text { Discrimination } \\ \text { Yes }\end{array} & 49(43.7) \\ \text { No } & 63(56.3) \\ \text { Sexual behaviour } & \\ \text { Homosexual } & 9(8) \\ \text { Bisexual } & 103(92)\end{array}$

$\mathrm{CD}^{+} \mathrm{T}$ cell count $\quad$ Mean $=498.5 \mathrm{SD}=191.6$ Range $=80-1100$

Medical follow up

attendance

\begin{tabular}{ll} 
Regular & $79(70.5)$ \\
Irregular & $33(29.5)$ \\
\hline
\end{tabular}

$\mathrm{CD}^{+}$cluster differentiation 4

34.31 and the mean of their $\mathrm{CD}^{+} \mathrm{T}$ cells was 498.5 $(\mathrm{SD}=191.6)$.

The participants who perceived discrimination reported significantly higher levels of severity of selfreported psychopathology and poorer HRQoL than those who did not perceive discrimination $(P<0.01)$. Moreover, the participants who reported low family income and lack of regular attendance with their medical follow-ups reported poorer HRQoL than those who had 
high-income levels and regular medical follow-ups $(P=$ 0.001 and $P=0.014$ respectively). Table 2 shows the differences between sociodemographic and clinical characteristics of MSM with HIV/AIDS in their self-reported psychopathology and HRQoL.

\section{Determinants of HRQoL}

\section{a. Psychopathology}

Table 3 illustrates the correlation between sociodemographic characteristics and psychopathologic symptoms among MSM with HIV/AIDS. For MSM with HIV/ AIDS, SCL 90 scores were significantly correlated with fear of discrimination $(P<0.01)$.

\section{b. HRQoL}

Table 4 shows the correlation of HRQoL among MSM with HIV/AIDS. Family income $(P<0.01)$, fear of discrimination $(P<0.01)$ and medical follow-up attendance $(P<0.05)$ were significantly correlated with WHO-HIV-Bref-QOL domains among MSM with HIV/ AIDS. In addition, subscales of SCL 90 (somatization, obsession, depression and phobia) and total scores of SCL 90 were found to be correlated with total scores of HRQoL.

\section{c. Predictors of self-reported psychopathology}

Total SCL 90 score explained $8.4 \%$ of variance $(R 2=$ 0.084 ). All measures of psychopathology were predicted by

Table 2 Differences between sociodemographic and clinical characteristics of MSM with HIV/AIDS, and their self-reported psychopathology and HRQoL

\begin{tabular}{|c|c|c|c|c|c|c|c|}
\hline \multirow[t]{2}{*}{ Characteristics of Patients } & \multicolumn{4}{|c|}{ Self-reported Psychopathology } & \multicolumn{3}{|l|}{ HRQoL } \\
\hline & $n(\%)$ & $M(S D)$ & $\mathrm{t} / \mathrm{F}$ & $P$ & $\mathrm{M}(\mathrm{SD})$ & $\mathrm{t} / \mathrm{F}$ & $P$ \\
\hline \multicolumn{8}{|l|}{ Marital status } \\
\hline Married/co-habiting & $16(14.3)$ & $2.22(0.81)$ & 2.345 & 0.101 & $10.50(3.14)$ & 0.148 & 0.862 \\
\hline Single & $78(69.6)$ & $2.24(0.80)$ & & & $10.79(3.13)$ & & \\
\hline Divorced/widowed & $18(16.1)$ & $1.81(0.51)$ & & & $11.11(3.95)$ & & \\
\hline \multicolumn{8}{|l|}{ Education level } \\
\hline Junior high school and below & $30(26.8)$ & $2.02(0.78)$ & 1.153 & 0.320 & $10.13(3.89)$ & 2.132 & 0.124 \\
\hline Secondary School & $35(31.3)$ & $2.31(0.83)$ & & & $10.40(2.82)$ & & \\
\hline College and above & $47(42)$ & $2.15(0.73)$ & & & $11.53(3.01)$ & & \\
\hline \multicolumn{8}{|l|}{ Monthly income } \\
\hline$<2000$ RMB & $36(32.1)$ & $2.32(0.75)$ & 1.127 & 0.328 & $9.28(3.42)$ & 7.857 & 0.001 \\
\hline 2000-4000 RMB & $50(44.6)$ & $2.12(0.78)$ & & & $11.12(2.95)$ & & \\
\hline$>4000 \mathrm{RMB}$ & $26(23.2)$ & $2.04(0.79)$ & & & $12.31(2.75)$ & & \\
\hline \multicolumn{8}{|l|}{ Employment } \\
\hline Yes & $84(75)$ & $2.11(0.76)$ & -1.307 & 0.194 & $11.00(3.13)$ & 1.109 & 0.270 \\
\hline No & $28(25)$ & $2.33(0.82)$ & & & $10.21(3.58)$ & & \\
\hline \multicolumn{8}{|l|}{ Living condition } \\
\hline Alone & $79(70.5)$ & $2.12(0.73)$ & -1.024 & 0.308 & $10.81(3.32)$ & 0.033 & 0.974 \\
\hline Co-resident & $33(29.5)$ & $2.28(0.86)$ & & & $10.79(3.12)$ & & \\
\hline \multicolumn{8}{|l|}{ Discrimination } \\
\hline Yes & $49(43.7)$ & $2.44(0.80)$ & 3.434 & 0.001 & $8.82(2.45)$ & -6.762 & 0.000 \\
\hline No & $63(56.3)$ & $1.95(0.69)$ & & & $12.35(2.95)$ & & \\
\hline \multicolumn{8}{|l|}{ Sexual behaviour } \\
\hline Homosexual & $9(8)$ & $2.14(0.78)$ & -0.124 & 0.901 & $10.67(3.16)$ & -0.131 & 0.896 \\
\hline Bisexual & $103(92)$ & $2.17(0.78)$ & & & $10.82(3.27)$ & & \\
\hline \multicolumn{8}{|l|}{ Medical follow ups } \\
\hline Regular & 79 (70.5) & $2.17(0.78)$ & 0.341 & 0.734 & $11.29(3.06)$ & 2.494 & 0.014 \\
\hline Irregular & $33(29.5)$ & $2.12(0.75)$ & & & $9.63(3.50)$ & & \\
\hline
\end{tabular}


Table 3 Self-reported psychopathology among MSM with HIV/AIDS

\begin{tabular}{|c|c|c|c|c|c|c|c|c|c|c|}
\hline \multirow[b]{2}{*}{ Sociodemographic characteristics } & \multicolumn{9}{|c|}{ SCL-90 domains } & \multirow[b]{2}{*}{ Total score } \\
\hline & Somatization & Obsession & Interpersonal & Depression & Anxiety & Hostility & Phobia & Paranoid & Psychotic & \\
\hline Age & -.044 & -.030 & .007 & -.051 & -.071 & -.099 & -.072 & -.096 & -.042 & -.044 \\
\hline Marital Status & -.125 & -.126 & -.165 & -.142 & -.147 & -.126 & -.160 & -.163 & $-.212^{*}$ & -.157 \\
\hline Education & .054 & .056 & .035 & .076 & .019 & -.040 & .022 & .098 & .050 & .054 \\
\hline Family Income & -.145 & -.153 & -.152 & -.075 & -.004 & -.185 & -.155 & -.122 & -.138 & -.145 \\
\hline Employment & .078 & $.187^{*}$ & .123 & .106 & .081 & .075 & .113 & .122 & .093 & .129 \\
\hline Living condition & .039 & .134 & -.026 & .082 & .093 & .166 & .041 & .106 & .030 & .072 \\
\hline Perceived discrimination & $-.289 * *$ & $-.360^{* *}$ & $-.261^{* *}$ & $-.287^{* *}$ & $-.257^{* *}$ & $-.217^{*}$ & $-.315^{* *}$ & $-.217^{*}$ & $-.274^{* *}$ & $-.320^{* *}$ \\
\hline Sexual behaviour & .018 & -.023 & -.056 & .053 & -.001 & .014 & -.066 & -.049 & .025 & .005 \\
\hline $\mathrm{CD} 4+\mathrm{T}$ cell count & -.045 & .114 & .009 & -.053 & .084 & .001 & .061 & .017 & .018 & -.045 \\
\hline Medical follow up & -.081 & -.021 & .048 & .023 & -.035 & -.042 & .036 & .062 & .015 & -.011 \\
\hline
\end{tabular}

Notes: ${ }^{*} P<0.05 ;{ }^{*} P<0.01$

the perception of discrimination. Interpersonal sensitivity was also predicted by marital status $(\beta=-0.251 ; P=0.041)$. Table 5 describes the predictors of self-reported psychopathology among MSM with HIV/AIDS.

\section{d. Predictors of health-related quality of life among MSM with HIV/AIDS}

All domains of HRQoL, except social domain, were predicted by family income. Social and spirituality domains, and total HRQoL were predicted by fear of discrimination $(\beta=0.404 ; \quad P<0.001, \quad \beta=0.218 ; \quad P=$ 0.049 and $\beta=0.433 ; P<0.001$ respectively). Medical follow-up attendance seems to be a significant predictor of physical, psychological and social domains,

Table 4 Health-related quality of life among MSM with HIV/AIDS

\begin{tabular}{|c|c|c|c|c|c|c|c|c|}
\hline & & \multicolumn{6}{|c|}{ WHO-HIV-Bref-QOL domains } & \multirow[b]{2}{*}{ Total QoL } \\
\hline & & Physical & Psychological & Independence & Social & Environment & Spirituality & \\
\hline \multirow[t]{10}{*}{ Sociodemographic characteristics } & Age & .072 & .031 & -.056 & -.057 & .020 & $.192^{*}$ & -.017 \\
\hline & Marital Status & .105 & .022 & -.034 & -.048 & .046 & .125 & .007 \\
\hline & Education & .048 & .065 & .143 & .114 & .136 & .033 & .184 \\
\hline & Family income & $.256^{* *}$ & $.306^{* *}$ & $.352^{* *}$ & $.284^{* *}$ & $.357^{* *}$ & $.298^{* *}$ & $.351^{* *}$ \\
\hline & Employment & -.111 & -.111 & -.049 & -.031 & -.120 & $-.199^{*}$ & -.092 \\
\hline & Living condition & .012 & .097 & .006 & .107 & -.015 & .087 & -.015 \\
\hline & Perceived discrimination & $.305^{* *}$ & $.200^{*}$ & $.352^{* *}$ & $.402^{* *}$ & $.409^{* *}$ & $.276^{* *}$ & $.570^{* *}$ \\
\hline & Sexual behavior & -.004 & -.038 & .056 & .055 & .034 & .018 & .044 \\
\hline & CD4 $+\mathrm{T}$ cell count & .050 & .147 & .026 & .168 & .038 & .112 & .053 \\
\hline & Medical follow up & $-.233^{*}$ & $-.280^{* *}$ & -.125 & -.116 & -.143 & -.160 & $-.233^{*}$ \\
\hline \multirow[t]{10}{*}{ SCL-90 } & Somatization & $-.223^{*}$ & -.134 & $-.258^{* *}$ & -.140 & $-.258^{* *}$ & -.138 & $-.230^{*}$ \\
\hline & Obsession & $-.264^{* *}$ & -.181 & -.177 & -.149 & $-.232^{*}$ & $-.260^{* *}$ & $-.257^{* *}$ \\
\hline & Interpersonal & -.181 & -.130 & -.107 & -.088 & -.174 & $-.225^{*}$ & -.152 \\
\hline & Depression & $-.208^{*}$ & $-.210^{*}$ & -.140 & -.089 & -.183 & $-.213^{*}$ & $-.197^{*}$ \\
\hline & Anxiety & $-.205^{*}$ & -.155 & -.134 & -.080 & -.157 & $-.193^{*}$ & -.169 \\
\hline & Hostility & -.041 & -.004 & -.015 & .053 & -.035 & -.077 & -.116 \\
\hline & Phobia & $-.233^{*}$ & $-.195^{*}$ & $-.211^{*}$ & -.094 & $-.230^{*}$ & $-.268^{* *}$ & $-.273^{* *}$ \\
\hline & Paranoid & -.147 & -.121 & -.139 & -.039 & -.163 & -.136 & -.179 \\
\hline & Psychotic & -.173 & -.168 & -.108 & -.042 & -.168 & $-.193^{*}$ & -.155 \\
\hline & Total SCL-90 score & $-.216^{*}$ & -.167 & -.164 & -.098 & $-.204^{*}$ & $-.212^{*}$ & $-.212^{*}$ \\
\hline
\end{tabular}


Table 5 Predictors of self-reported psychopathology among MSM with HIV/AIDS

\begin{tabular}{|c|c|c|c|c|c|c|}
\hline Subscales & Item & $\beta$ & $T$ & $P$ & $\Gamma^{2}$ & $95 \% \mathrm{Cl}$ \\
\hline Somatization & Perceived discrimination & -0.308 & -3.118 & 0.002 & 0.048 & $-0.880 \sim-0.196$ \\
\hline Obsession & Perceived discrimination & -0.327 & -3.419 & 0.001 & 0.111 & $-0.887 \sim-0.236$ \\
\hline \multirow[t]{2}{*}{ Interpersonal sensitivity } & Marital status & -0.251 & -2.065 & 0.041 & 0.049 & $-0.553 \sim-0.011$ \\
\hline & Perceived discrimination & -0.214 & -2.164 & 0.033 & & $-0.699 \sim-0.030$ \\
\hline Depression & Perceived discrimination & -0.224 & -2.250 & 0.027 & 0.035 & $-0.801 \sim-0.050$ \\
\hline Anxiety & Perceived discrimination & -0.250 & -2.520 & 0.013 & 0.037 & $-0.812 \sim-0.097$ \\
\hline Hostility & Perceived discrimination & -0.225 & -2.253 & 0.026 & 0.029 & $-0.670 \sim-0.043$ \\
\hline Phobia & Perceived discrimination & -0.254 & -2.594 & 0.011 & 0.066 & $-0.752 \sim-0.100$ \\
\hline Psychotic & Perceived discrimination & -0.238 & -2.414 & 0.018 & 0.050 & $-0.684 \sim-0.067$ \\
\hline Total SCL 90 scores & Perceived discrimination & -0.282 & -2.881 & 0.005 & 0.065 & $-0.740 \sim-0.137$ \\
\hline
\end{tabular}

and total HRQoL. Table 6 illustrates the predictors of health-related quality of life among MSM with HIV/AIDS.

\section{Discussion}

This study presents prevalent bisexual preferences among HIVMSM in Dalian. The findings from this study demonstrate that $92 \%$ of the HIVMSM were bisexuals while only $8 \%$ were homosexuals. Culturally, homosexuality is an unacceptable behaviour in China [19], which could be a reason for the high bisexual preference to cover up and decrease the pressure from the society.

In this study, MSM who reported the perception of discrimination had a higher level of severity of psychopathology $(P=0.001)$ and poor HRQoL $(P<0.001)$. This could be attributed to internalization of negative attitudes and assumptions of guilt, inferiority and lack of self-worth [31], which may lead to self-blame and self-isolation due to perceived discrimination, probably exacerbating hostility to social environments. Evidence from a published report revealed that a hostile social environment has an impact on mental health and QOL as homosexuals reported higher levels of sexual minority-specific victimization, depressive symptoms, and suicidality compared to the heterosexuals [32].

A survey from Jinan, Qingdao, and Yantai of Shandong province in China concluded that the bisexual behaviour is independently associated with higher levels of HIV/ AIDS-related discrimination [33]. Social $(P<0.001)$ and spirituality $(P=0.049)$ domains, and total HRQoL $(P<$ 0.001 ) were predicted by perceived discrimination. On the other hand, self-reported symptoms; somatization

Table 6 Predictors of health-related quality of life among MSM with HIV/AIDS

\begin{tabular}{|c|c|c|c|c|c|c|}
\hline Domain & Item & $\beta$ & $T$ & $P$ & $\Gamma^{2}$ & $95 \% \mathrm{Cl}$ \\
\hline \multirow[t]{3}{*}{ Physical } & Marital status & 0.307 & 2.269 & 0.026 & 0.184 & $0.160 \sim 2.472$ \\
\hline & Family income & 0.236 & 2.115 & 0.038 & & $0.062 \sim 2.073$ \\
\hline & Medical follow-up & -0.211 & -2.045 & 0.045 & & $-3.148 \sim-0.040$ \\
\hline \multirow[t]{2}{*}{ Psychological } & Monthly family income & 0.319 & 2.901 & 0.005 & 0.200 & $0.405 \sim 2.181$ \\
\hline & Medical follow-up & -0.342 & -3.372 & 0.001 & & $-3.675 \sim-.945$ \\
\hline Independence & Monthly family income & 0.332 & 3.111 & 0.003 & 0.244 & $0.553 \sim 2.522$ \\
\hline \multirow[t]{4}{*}{ Social } & Monthly family income & 0.266 & 2.629 & 0.010 & 0.328 & $0.285 \sim 2.070$ \\
\hline & Living condition & 0.256 & 2.742 & 0.008 & & $0.522 \sim 3.301$ \\
\hline & Perceived discrimination & 0.404 & 4.088 & 0.000 & & $1.411 \sim 4.095$ \\
\hline & Medical follow-up & -0.194 & -2.067 & 0.042 & & $-2.810 \sim-0.051$ \\
\hline Environment & Monthly family income & 0.290 & 2.631 & 0.010 & 0.192 & $0.286 \sim 2.073$ \\
\hline \multirow[t]{2}{*}{ Spirituality } & Monthly family income & 0.265 & 2.373 & 0.020 & 0.185 & $0.208 \sim 2.395$ \\
\hline & Perceived discrimination & 0.218 & 2.004 & 0.049 & & $0.009 \sim 3.296$ \\
\hline \multirow[t]{3}{*}{ Total HRQoL } & Monthly family income & 0.231 & 2.359 & 0.021 & 0.364 & $0.159 \sim 1.890$ \\
\hline & Perceived discrimination & 0.433 & 4.521 & 0.000 & & $1.649 \sim 4.247$ \\
\hline & Medical follow-up & -0.225 & -2.488 & 0.015 & & $-2.991 \sim-0.331$ \\
\hline
\end{tabular}


$(P<0.05)$, obsession $(P<0.01)$, depression $(P<0.05)$, phobia $(P<0.01)$ and overall SCL 90 scores $(P<0.05)$ were significantly correlated with total quality of life (TQOL). A similar study among the individuals living with HIV/AIDS reported significant associations between poor HRQoL and a high degree of depression, anxiety, anger and low self-confidence [13]. Homosexuality is taboo in China, and therefore, MSM often feel guilt, low self-esteem, and fear of discrimination, which may eventually lead to depression and decreased HRQoL $[34,35]$. The negative impact of depression in QOL among people living with HIV/ AIDS and its role in disease progression has been described before [36, 37]. The present study shows that all subscales of SCL 90 including total SCL 90 score were predicted by perceived discrimination. The selfreported psychopathology due to the experience of perceived discrimination may affect the HRQoL of the HIVMSM through: (i) impairing their self-esteem and self-confidence, (ii) worsening their stress, (iii) increasing unemployment that can affect their income level, (iv) increasing social withdrawal that can result in loneliness and poor medical follow-up attendance, and (v) decreasing their motivation that may result in selfcare deficit and poor self-image. The poor HRQoL observed among HIVMSM in this study could benefit from psychological and social support.

Lack of proper medical follow-up emerged as a significant predictor of physical $(P=0.045)$, psychological $(P=0.001)$, social domains $(P=0.042)$ and total HRQoL $(P=0.015)$ in this study. Medical check-ups provide a better opportunity to the people living with HIV/AIDS to communicate with the health professional on their medications and any concerns regarding their physical and mental health. One qualitative study in Zambia identified lack of follow-up and counselling as a barrier to patient's adherence to ART [38]. Hence, follow-up and counselling should be strengthened to provide the information about ART and better comprehensive medical check-ups.

The persistent influence of family income in HRQoL between HIVMSM observed in this study and ordinary HIV/AIDS cases from the previous studies might show the exposure of the same influential or risk factors that are associated with socioeconomic status. High family income [39] and unemployment [15] have positive and negative associations respectively with QOL among people living with HIV/AIDS. Furthermore, economic satisfaction and family support were reported among the conditions that can positively influence HRQoL among the adults with HIV/AIDS [40].

The findings from our study provide primary predictors (perceived discrimination, low-income, and irregular medical follow-up) that are associated with psychopathology and poor HRQoL, and the corresponding proportions of the sexual behaviours among the MSM with HIV/AIDS. The understanding of the correlations and predictors that may impact the mental wellbeing and quality of life among the HIVMSM is essential for improving the continuum of healthcare plan for MSM in Dalian. This will foster the accessibility of HIVMSM to HIV patient care and consequently contribute to the healthcare policy development regarding the prevention and intervention. HIV transmission among MSM is surging in China and our current study revealed significantly high psychopathological symptoms and poor HRQoL among HIVMSM who have reported perceived discrimination.

This study has several limitations. First, this study is subjected to self-reported data. Second, there was no confirmatory assessment that can prove the presence or severity of psychopathology, and the magnitude of the perception of discrimination in addition to the participants' report. The strength of this study lies in its broad representative samples for the recorded HIVMSM and the use of a standardized instrument.

\section{Conclusion}

According to this study total quality of life was predicted by family income, perceived discrimination and medical follow-up attendance whereas self-reported psychopathology was predicted by perceived discrimination. To reduce the psychopathologic symptoms among HIVMSM, social and psychological support is of crucial importance to improve HRQoL in this targeted population. More needs to be emphasized on the newly diagnosed HIVMSM in Dalian in order to develop a more targeted intervention to prevent perceived discrimination and lack of proper medical follow-up services. The strategies targeting MSM and focusing on linking and engaging HIV-positive patients in a healthcare are the keys to bridging the steps to improving HIV healthcare. This can be accomplished by establishing free HIV care, advocacy for MSM with HIV-positive by health professionals, and extending community health education to avoid stigma and discrimination from the society in order to improve the mental wellbeing and health-related quality of life.

\section{Additional file}

Additional file 1: Multilingual abstracts in the five official working languages of the United Nations. (PDF $738 \mathrm{~kb}$ )

\section{Abbreviations}

AIDS: Acquired immunodeficiency syndrome; ART: Anti-retroviral therapy; CD4: Cluster differentiation 4; HAART: Highly active anti-retroviral therapy; HIV: Human immunodeficiency virus; HRQoL: Health related quality of life; MSM: Men who have sex with men; QOL: Quality of life; SCL 90: Symptom 
check list 90; WHO: World Health Organization; WHOQOL-HIV-Bref: World Health Organization quality of life in HIV infection

\section{Acknowledgements}

We would like to thank Prof. Qing-Hua Sun and Dr. Dishon Muloi for critically reviewing the manuscript. In addition, we would like to thank Mrs. Jerry Stephens, Anesh Arvind Chand and Mr. Bright Eric for their English editing.

\section{Funding}

None.

\section{Availability of data and materials}

No additional data are available.

\section{Authors' contributions}

$\mathrm{THH}$ contributes to the conception and design, data analysis and interpretation and manuscript drafting and revision. FW, SL, YJ, MC and WT are involved in data analysis, interpretation and manuscript drafting. $\mathrm{XL}$ participates in the design and coordination, and drafts the manuscript. All authors agree to be accountable for all aspects of the work and have read and approved the final manuscript.

\section{Authors' information}

$\mathrm{TTH}, \mathrm{FW}, \mathrm{SL}$ and $\mathrm{YJ}$ are masters' students in Epidemiology and Biostatistics. $\mathrm{MC}$ is a professor in the School of Public Health at Dalian Medical University. WT is a professor in the School of Public Health and in the Department of HIV/ AIDS at Dalian Center for Disease Control and Prevention. XL is a professor of Epidemiology and senior research supervisor at Dalian Medical University.

\section{Competing interests}

The authors declare that they have no competing interests.

\section{Ethics approval and consent to participate}

Ethical approval to conduct the study was obtained from the Ethics Committees of Dalian Medical University and Dalian CDC. The participation was voluntary and written informed consent was obtained from each of the participants prior to the interview.

\section{Author details}

${ }^{1}$ Department of Epidemiology and Biostatistics, Dalian Medical University, Dalian, Liaoning 116044, People's Republic of China. 'School of Public Health, Dalian Medical University, Dalian, Liaoning 116044, People's Republic of China. ${ }^{3}$ Department of HIV/AIDS, Dalian Center for Disease Control and Prevention, Dalian 116023, Liaoning, People's Republic of China.

\section{Received: 29 December 2015 Accepted: 24 October 2016}

\section{Published online: 01 December 2016}

\section{References}

1. Qi J, Zhang D, Fu X, Li C, Meng S, Dai M, et al. High risks of HIV transmission for men who have sex with men: a comparison of risk factors of HIV infection among MSM associated with recruitment channels in 15 cities of China. PLoS One. 2015;10(4):e0121267. doi:10.1371/journal.pone.0121267.

2. Shang $H, X u$ J, Han X, Spero Li J, Arledge KC, Zhang L. HIV prevention: bring safe sex to China. Nature. 2012:485(7400):576-7.

3. Zhang B, Li X, Shi T. A primary estimation of the number of population and HIV prevalence in homosexual and bisexual men in China. J China AIDS/STD Prevent Control. 2002;8:197.

4. Zhang L, Chow EP, Jing J, Zhuang X, Li X, He M, et al. HIV prevalence in China: integration of surveillance data and a systematic review. Lancet Infect Dis. 2013:13(11):955-63.

5. $\quad$ Tang S, Tang W, Meyers K, Chan P, Chen Z, Tucker JD. HIV epidemiology and responses among men who have sex with men and transgender individuals in China: a scoping review. BMC Infect Dis. 2016:16(1):588.

6. State Council AIDS Working Committee Office (SCAWCO). China 2010 UNGASS country progress report (2008-2009). Beijing: Ministry of Health of the People's Republic of China; 2010.

7. Ministry of Health, People's Republic of China, Joint United Nations Programme on HIV/AIDS, and World Health Organization. Update on the AIDS/STD epidemic in China and main response in control and prevention in October, 2014. Chin J AIDS STD. 2014;20(12):885.
8. Chow EPF, Lau JTF, Zhuang X, Zhang X, Wang Y, Zhang L. HIV prevalence trends, risky behaviours, and governmental and community responses to the epidemic among men who have sex with men in China. BioMed Res Int. 2014. doi:10.1155/2014/607261.

9. Zhao Z, Wan Y, Zhou L, Li D, Chang B. HIV/AIDS sentinel surveillance in men who have sex with men in Dalian, Liaoning, 2009-2012. Dis Surv. 2014. doi:10.3784/j.

10. Miners AH, Sabin CA, Mocroft A, Youle M, Fisher M, Johnson M. Healthrelated quality of life in individuals infected with HIV in the era of HAART. HIV Clin Trials. 2001;2(6):484-92.

11. Gregory SZ, Ahmed MB, Margaret LB, Douglas KO. The cost effectiveness of counseling strategies to improve adherence to highly active antiretroviral therapy (HAART) among men who have sex with men. Med Decis Making. 2008;28(3):359-76

12. Patterson DL, Swindells $S$, Mohr J, Brester M, Vergis EN, Squier C, et al. Adherence to protease inhibitor therapy and outcomes in patients with HIV infection. Ann Intern Med. 2000;133(1):21-30.

13. Burgess AP, Carretero M, Elkington A, Pasqual-Marsettin E, Lobaccaro C, Catalan J. The role of personality, coping style and social support in healthrelated quality of life in HIV infection. Qual Life Res. 2000;9:423-37.

14. Penedo FJ, Gonzalez JS, Dahn JR, Antoni M, Malow R, Costa P, et al. Personality, quality of life and HAART adherence among men and women living with HIV/AIDS. J Psychosom Res. 2003;54:271-8.

15. McGowan J, Sherr L, Rodger A, Fisher M, Miners A, Johnson M, et al. Effects of age on symptom burden, mental health and quality of life amongst people with HIV in the UK. J Int AIDS Soc. 2014;17 Suppl 3:19511.

16. Xu X, Sheng Y, Khoshnood K, Clark K. Factors Predicting Internalized Stigma among Men Who Have Sex with Men Living with HIV in Beijing, China. J Assoc Nurses AIDS Care. 2016. doi:10.1016/j.jana.2016.08.004.

17. Bouhnik AD, Preau M, Schiltz MA, Peretti-Watel P, Obadia Y, Lert F, et al. Unsafe sex with casual partners and quality of life among HIV-infected gay men: evidence from a large representative sample of outpatients attending French hospitals (ANRS-EN12-VESPA). Acquir Immune Defic Syndr. 2006;42:597-603.

18. Feng MC, Feng JY, Chen TC, Lu PL, Ko NY, Chen YH. Stress, needs, and quality of life of family members caring for adults living with HIV/AIDS in Taiwan. AIDS Care. 2009:21:482-9.

19. Sun W, Wu M, Qu P, Lu C, Wang L. Depressive symptoms in people living with HIV: related factors psychological well-being of people living with HIV/ AIDS under the new epidemic characteristics in China and the risk factors: a population-based study. Int J Infect Dis. 2014;28:e147-52.

20. Zhou W, Zhao M, Wang X, Schilling RF, Zhou S, Qiu HY, et al. Treatment adherence and health outcomes in MSM with HIV/AIDS: patients enrolled in 'One-Stop' and standard care clinics in Wuhan China. PLoS One. 2014 doi:10.1371/journal.pone.0113736

21. Benjamin O, Soraya S, Dan JS. Persistence of psychiatric disorders in a cohort of HIV/AIDS patients in South Africa: a 6-month follow-up study. I Psychosom Res. 2006:61:479-84.

22. Sun W, Wu M, Qu P, Lu C, Wang L. Quality of life of people living with HIV/ AIDS under the new epidemic characteristics in China and the associated factors. PLoS One. 2013;8(5):e64562.

23. Wang X, Wang Q, Yang X. Quality of life and related factors among 1194 AIDS patients receiving HAART in Yunnan province. Chin J AIDS STD. 2011; 17:499-502 [Article in Chinese].

24. Ding H, Liu J, Xu J, He Y, Guo X. Analysis on quality of life and related factors among people living HIV/AIDS. Chin J AIDS STD. 2012;18:14-7 [Article in Chinese].

25. Ma L, Xu P, Lin H, Lahong J, Fan L. Quality of life of people living with HIV/ AIDS: a cross-sectional study in Zhejiang province, China. PLoS One. 2015; 10(8):e0135705

26. Hsiung $P C$, Fang $C T$, Wu CH, Sheng WH, Chen SC, Wang JD, Yao G. Validation of the WHOQOL-HIV BREF among HIV-infected patients in Taiwan. AIDS Care. 2011:23(8):1035-42.

27. Sun HM, Zhang JJ, Fu XD. Psychologic status, coping, and social support of people living with HIV/AIDS in central China. Public Health Nurs. 2007:24:132-40.

28. Tang Q, Cheng Z, Yuan A, Zheng Y. The use and reanalysis of SCL90 in China. Chin J Clin Psych. 1999:7(1):16.

29. Jin C, Zhao G, Zhang F, Feng L, Wu N. The psychological status of HIVpositive people and their psychosocial experiences in eastern China. HIV Med. 2010;11(4):253-9.

30. Hao yuan-tao FJ-q. The introduce and usage of WHOOOL instrument in Chinese. Mod Rehabil. 2000;4(8):1127-9,45. 
31. Ross MW, Berg RC, Schmidt AJ, Hospers HJ, Breveglieri M, Furegato M, et al. Internalized homonegativity predicts HIV-associated risk behavior in European men who have sex with men in a 38-country cross-sectional study: some public health implications of homophobia. BMJ Open. 2013. doi:10.1136/bmjopen-2012-001928.

32. Burton CM, Marshal MP, Chisolm DJ, Sucato GS, Friedman MS. Sexual minority-related victimization as a mediator of mental health disparities in sexual minority youth: a longitudinal analysis. J Youth Adolesc. 2013; 42(3):394-402.

33. Liao $M$, Wang $M$, Shen $X$, Huang $P$, Yang $X$, Hao L, et al. Bisexual behaviors, HIV knowledge, and stigmatizing/discriminatory attitudes among men who have sex with men. PLoS One. 2015;10(6):e0130866.

34. Li J, Mo PK, Kahler CW, Lau JT, Du M, Dai Y, Shen H. Prevalence and associated factors of depressive and anxiety symptoms among HIV-infected men who have sex with men in China. AIDS Care. 2015;21:1-6.

35. Liu J, Qu B, Zhu Y, Hu B. The influence of social support on quality of life of men who have sex with men in China: a preliminary study. PLoS One. 2015; 10(5):e0127644.

36. Gore-Felton C, Koopman C, Spiegel D, Vosvick M, Brondino M, Winningham A. Effects of quality of life and coping on depression among adults living with HIV/AIDS. J Health Psychol. 2006;11:711-29.

37. Simoni JM, Safren SA, Manhart LE, Lyda K, Grossman Cl, Rao D, et al. Challenges in addressing depression in HIV research: assessment, cultural context, and methods. AIDS Behav. 2011;15:376-88.

38. Sanjobo N, Frich JC, Fretheim A. Barriers and facilitators to patients' adherence to antiretroviral treatment in Zambia: a qualitative study. SAHARA J. 2008:5(3):136-43.

39. Wang DM, Ding X, CHEN QF, et al. Quality of life and medical care needs of people living with HIV/AIDS in Chongqing. National center for AIDS \& STD control and prevention, China CDC, Beijing 100050, China. Chin J AIDS STD. 2006;12(6):492 (Article in Chinese).

40. Jaiberth CA, Luz PV, Juan LS, Marcela DM, Oscar LA. Health related quality of life in adults with HIV/AIDS in Colombia, 2009. Biomedica. 2011:31:532-44.

\section{Submit your next manuscript to BioMed Central and we will help you at every step:}

- We accept pre-submission inquiries

- Our selector tool helps you to find the most relevant journal

- We provide round the clock customer support

- Convenient online submission

- Thorough peer review

- Inclusion in PubMed and all major indexing services

- Maximum visibility for your research

Submit your manuscript at www.biomedcentral.com/submit

) Biomed Central 